\title{
Percutaneous coronary intervention equates to placebo procedure in stable angina?
}

\author{
Hai-Long Dai ${ }^{1,2}$, Xue-Feng Guang ${ }^{1}$, Zhi-Cheng Jing ${ }^{2}$ \\ ${ }^{1}$ Key Laboratory of Cardiovascular Disease of Yunnan Province, Department of Cardiology, Yan'an Affiliated Hospital of Kunming Medical \\ University, Kunming 650000, China; ${ }^{2}$ Key Laboratory of Pulmonary Vascular Medicine \& FuWai Hospital, State Key Laboratory of Cardiovascular \\ Disease, National Center for Cardiovascular Diseases, Chinese Academy Medical Sciences \& Peking Union Medical College, Beijing 100037, China \\ Correspondence to: Hai-Long Dai, MD, PhD. Key Laboratory of Cardiovascular Disease of Yunnan Province, Department of Cardiology, Yan'an \\ Affiliated Hospital of Kunming Medical University, Kunming 650000, China. Email: dhlkm@qq.com.
}

Submitted Apr 05, 2018. Accepted for publication Oct 18, 2018.

doi: $10.21037 /$ jtd.2018.11.36

View this article at: http://dx.doi.org/10.21037/jtd.2018.11.36

A study published in the international journal the Lancet found that percutaneous coronary intervention (PCI) did not improve exercise capacity and symptoms compared with a placebo procedure in patients with medically treated angina and severe coronary stenosis (1). This is a landmark rigorous study, which is the first placebo-controlled trial of PCI for stable angina. However, there are still some limitations, this trial should be interpreted with caution.

Firstly, dobutamine stress echocardiography (DSE) wall motion score index (WMSI) can predict improvement of left ventricular function (2), early coronary revascularization was associated with better outcomes in patients with abnormal DSE WMSI (3). In this study, patients with anatomically and haemodynamically severe coronary stenosis, DSE WMSI was improved in patients who underwent PCI, whether PCI can improve ventricular remodeling and heart function, which require further investigation and long-term follow-up data.

Secondly, in this study, compared to placebo group, in PCI group, exercise time increment was improved (SD 11.8, 95\% CI: -7.8 to 31.3 vs. 28.4 , 95\% CI: $11.6-45.1, \mathrm{P}=0.20$ ), but not statistically significant. The fractional flow reserve (FFR) threshold to recognize a clinically significant lesion level is 0.75 (4) or 0.80 (5), however, 57 (29\%) patients had FFR greater than 0.80 and 64 (32\%) had instantaneous wave-free ratio (iFR) greater than 0.89 in this study, what was the result of exercise time increment in patients with FFR $<0.80$ and iFR $<0.89$ ? Moreover, we look forward to future analysis from the ORBITA investigators, finding that the cutoff value of FFR and iFR for angina relief in stable coronary artery disease, which may be another highlight of the ORBITA study.

\section{Acknowledgements}

Funding: This work was supported by Natural Science Foundation of Yunnan [2017FE467(-199)]; and the Health Talent Program of Yunnan [H201611, 2016-SW(sheng)-27, 2018HB105].

\section{Footnote}

Conflicts of Interest: The authors have no conflicts of interest to declare.

\section{References}

1. Al-Lamee R, Thompson D, Dehbi HM, et al. Percutaneous coronary intervention in stable angina (ORBITA): a double-blind, randomised controlled trial. Lancet 2018;391:31-40.

2. Wever-Pinzon O, Bangalore S, Romero J, et al. Inotropic contractile reserve can risk-stratify patients with HIV cardiomyopathy: a dobutamine stress echocardiography study. JACC Cardiovasc Imaging 2011;4:1231-8.

3. Boiten HJ, Ekmen H, Zijlstra F, et al. Impact of Early Coronary Revascularization on Long-Term Outcomes in Patients With Myocardial Ischemia on Dobutamine Stress Echocardiography. Am J Cardiol 2016;118:635-40.

4. Bech GJ, De Bruyne B, Pijls NH, et al. Fractional flow reserve to determine the appropriateness of angioplasty in moderate coronary stenosis: a randomized trial. 
Circulation 2001;103:2928-34.

5. Tonino PA, De Bruyne B, Pijls NH, et al. Fractional flow

Cite this article as: Dai HL, Guang XF, Jing ZC. Percutaneous coronary intervention equates to placebo procedure in stable angina? J Thorac Dis 2018;10(12):E808-E809. doi: 10.21037/ jtd.2018.11.36 reserve versus angiography for guiding percutaneous coronary intervention. N Engl J Med 2009;360:213-24. 